\title{
Filling with the Graphene Nanoplates as a Way to Improve Properties of Epoxy-Composites for Industrial and Geophysical Machinery
}

\author{
Dmitro Starokadomsky ${ }^{1}$, Anatoly Ishenko², Maria Reshetnyk ${ }^{3}$ \\ ${ }^{1}$ Composite Laboratory, Chuiko Institute of Surface Chemistry, National Academy of Sciences, Kiev, Ukraïna \\ ${ }^{2}$ Department of Machines for Black Metallurgy, Priazovsky State Technologic University (PGTU), Mariupol, Ukraïna \\ ${ }^{3}$ Geophysical Section, National Nature Muzeum, Kiev, Ukraïna
}

Email address:

km17@ua.fm (D. Starokadomsky)

\section{To cite this article:}

Dmitro Starokadomsky, Anatoly Ishenko, Mary Reshetnyk. Filling with the Graphene Nanoplates as a Way to Improve Properties of EpoxyComposites for Industrial and Geophysical Machinery. American Journal of Physics and Applications. Vol. 5, No. 6, 2017, pp. $120-125$. doi: 10.11648/j.ajpa.20170506.19

Received: November 11, 2017; Accepted: December 5, 2017; Published: January 3, 2018

\begin{abstract}
It is established that the filling with graphenes increases (by 1.3-1.8 times) the strength at normal adhesion to steel. At same time, filling reduces the compressive strength and abrasion resistance and also resistance to aggressive liquids (conc. nitric acid, chloromethylene; mixture acetone-ethylacetate). The most probable reason for this may be the features of the graphene plate structure, prone to deactivation (self-rotation) of particles and therefore sensitive to the technology of hardening. Studies have shown the limited positive effects of graphene as a filler of epoxydes, although its introduction can significantly improve certain practical characteristics (adhesion, thermal and electrical conductivity).
\end{abstract}

Keywords: Epoxy-Resin, Graphene, Compressive Strength, Bending, Adhesion, Swelling, Thermograms

\section{Introduction}

Graphene is a new type of carbon materials, that forms 2Dstructures. Structurally graphenes are monoatomic folias from sp2- gybride atoms of $\mathrm{C}$, packed in two-dimension cell structures with distance of $\mathrm{C}-\mathrm{C}$ even $0,142 \mathrm{~nm}$. He has very high electro- and thermo-conductivity. Therefore, the specific structure of graphene can result in creation of electroconducted composites and substantial his strengthening, in particular strengthening of adhesion to the metallic surfaces.

Theoretical predictions of their existence have been made for a long time. But as the graphene material was discovered only in the last decade - by A. Geim and V. Novosělov (exsoviet physicists who received the Nobel Preemie for this) [1]. Immediately, its unusual properties were discovered [217], after which a boom in the research of graphene-polymer and other systems began.

The introduction of graphene into polyepoxide leads (according to our data) to the formation of beautiful glossy coatings (figure 1). This allows you to count on graphene as an additive for simple (without complex technologies and temperatures) manufacturing of aesthetic plastic cases, parts, thermal bonding glues for appliances and machines. High interest in such coatings and compounds is shown by manufacturers of mobile communication and geological equipment, as well as large-scale engineering

\section{Methods \& Reactives}

\subsection{Preparation and Structure of Graphene}

Obtaining of lamellar plates (FLG-plates, figure 1) of graphenes from graphite flakes was carried according to the method of solubilisation, improved by Shulga-Ogenko [2]. The scales were filtered, washed first with a distillate, and then three times with ethanol, and dried. Then they were dispersed in boiling ethanol $(8 \mathrm{~g} / \mathrm{l})$ and processed with 20 $\mathrm{kHz}$ ultrasound until a stable suspension (in which they are stored permanently) is formed.

\subsection{Preparation of Composites}

Alcoholic solutions (based on the dispersion of graphite in 
alcohol) of the $2015 \mathrm{~g}$ series with specific weights of 8 and $31 \mathrm{~g} / 1$ were used.

The epoxy resin Epoxy-520 (Czech prod., EU) was mixed with an alcohol solution of graphene in proportions of 0.01 to $5 \mathrm{wt} \%$ from EtOH-solutions. The curing was carried out with the polyamine PEPA (resin: PEPA = 7:1) after 2 weeks of preparation. Cured composites were poured into molds or smeared with a thin layer on the bonded surfaces. After 5 days, they (except swelling samples) were treated at $75^{\circ} \mathrm{C}$ for 3 hours.

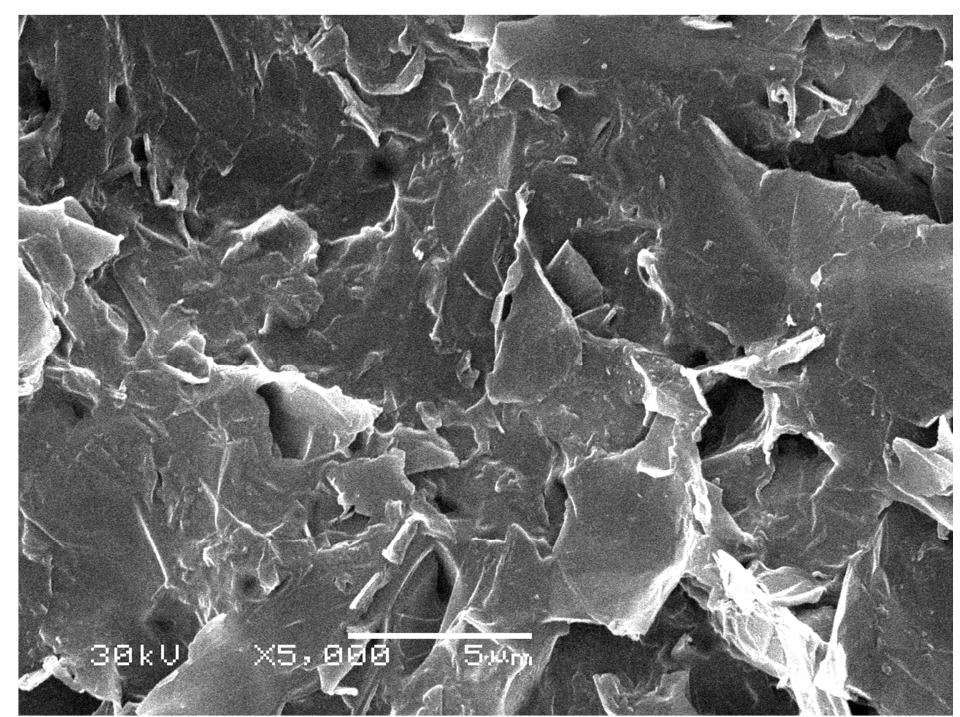

Figure 1. SEM-image of our graphene.

\subsection{Strength Tests}

The tests on compression and tensile (flexural) strength, and tests on tearing adhesion to steel were used (figure 2). The templates-cylinders $\mathrm{d}=8 \mathrm{~mm}, \mathrm{~h}=12 \mathrm{~mm}$ were compressed. For tensile (flexural) strength, templates-plates $60 \times 10 \times 2 \mathrm{~mm}$ were tested. For adhesion, steel cylinders $\left(5 \mathrm{~cm}^{2}\right)$ were clued and teared. Abrasion were measured as mass-loss at wear by P60-paper (wear way is $60 \times 20 \mathrm{~cm}$ ).

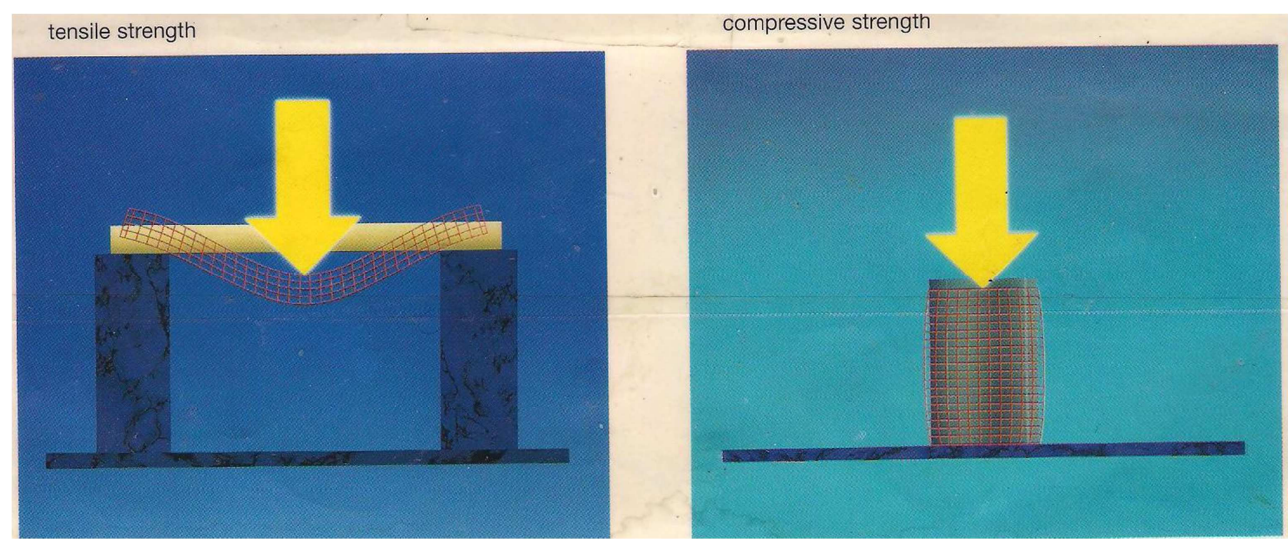

Figure 2. Visualisation of test methods.

\section{Result and Discussion}

\subsection{IR-Spectroscopy and Microscopy}

From the IR spectra it is seen that after $2 \mathrm{wt} \%$-filling the intensity of signals increases (only the peaks of the original olygomer are weakened at $1880-2089 \mathrm{~cm}^{-1}$, Figure 2), although their number and location are practically not changes. Considering that the signals for $1040,1083,1250 \mathrm{~cm}^{-1}$ and others (see table 1) are the most characteristic for a cured epoxy resin, it is possible to assume deeper polymerization after filling.

According identification of DobrotvorlStarokadomsky [1819], IR of cured composites show the change (intensification) of the intensities of the bands after filling (Figue 2). Thus, in the unfilled band, $573 \mathrm{~cm}^{-1}$ is clearly visible, according to [19, 20] (see Table 1) characteristic of the uncured epoxy olygomer. But in spectra of epoxy-graphene, it is replaced by a strong $560 \mathrm{~cm}^{-1}$ - signal of the polymer (see table 1). Similarly, the signal of the uncured in the unfilled at $1043 \mathrm{~cm}^{-1}$ is inferior to the polymer signal at $1043 \mathrm{~cm}^{-1}$ (Figure 3). Also, in filled the signal - at $833 \mathrm{~cm}^{-1}$ (for polymer) is much stronger. 


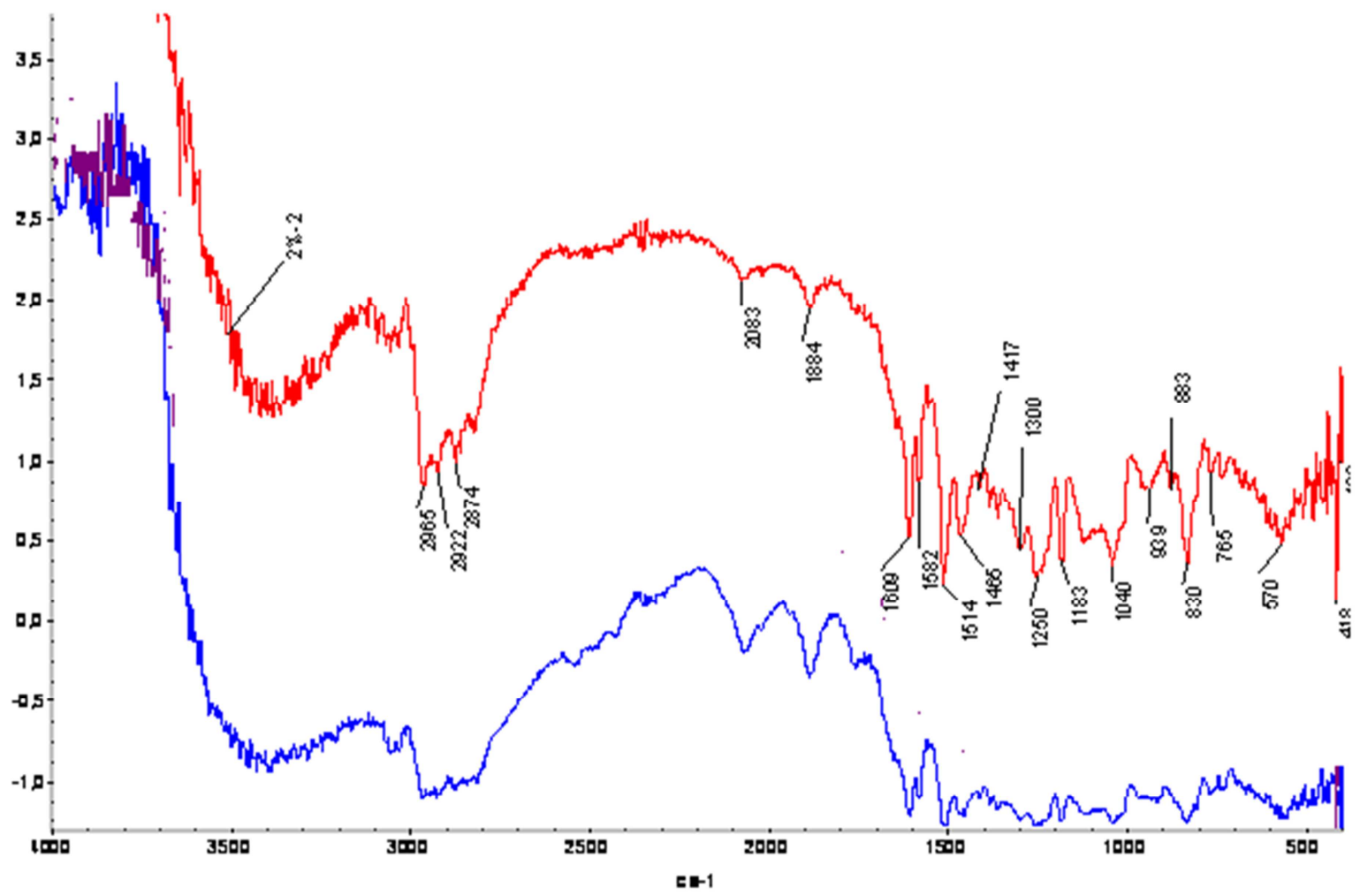

Figure 3. IR-reflection spectra for unfilled (bottom) and filled with $2 w t \%$ of graphene (upper).

The signals of the epoxy groups $(844,1260,1362$ and $1384 \mathrm{~cm}^{-1}$ etc.) do not appear in all the spectra, i.e. curing can be considered very complete (for epoxydes it is near 95\%). At the same time, the presence of distinct bands at 574 and $1888 \mathrm{~cm}^{-1}$, and especially epoxy groups at $2068 \mathrm{~cm}^{-1}$ (and also weak signals in the region of $2100-2812 \mathrm{~cm}^{-1}$ ) suggests that even in composites there is an appreciable fraction of uncured resin, who decreases with filling (Table 1). All this can speak of a better curing of a filled composite than an unfilled one.

Table 1. Characteristic of some IR signals of the epoxy ED20-hardener"system.

\begin{tabular}{ll}
\hline Signal according [19] (and our analogue), $\mathbf{c m}^{-1}$ & Identification [19-20] \\
\hline $554(560)$ & Epoxy-polymer, valent. CH2- \\
$574(573)$ & Initial epoxy-olygomer, valent.-CH2- \\
$828(833)$ & Polymer, pendulum oscillation -NH- \\
$1036(-)$ & Polymer, benzol rings and valent wobbles of CN-groups. \\
$1044(1043)$ & Initial epoxy-olygomer, benzol rings \\
$1180(1184)$ & Polymer, amino-groups \\
$1254(1254)$ & Polymer, OH- or amino-groups \\
$1260(-)$ & Initial epoxy-olygomer, epoxy CO-groups \\
$1310(1310)$ & Polymer, OH- or amino-groups \\
$1462(1457)$ & Polymer, benzol rings \\
$1510(1514)$ & Polymer, amino-groups \\
$1608(1608)$ & Polymer, primary amino-groups \\
$1610(-)$ & Hardener PEPA, valent. -CH3C- + -C-C- \\
$1890(1888)$ & Initial epoxy-olygomer, valent -CH- \\
$2068(2068)$ & Initial epoxy-olygomer, valent. epoxy-groups \\
$2968(2964)$ & Polymer, valent.-CH2-, -CH-, -OH -, -CH3C- \\
\hline
\end{tabular}




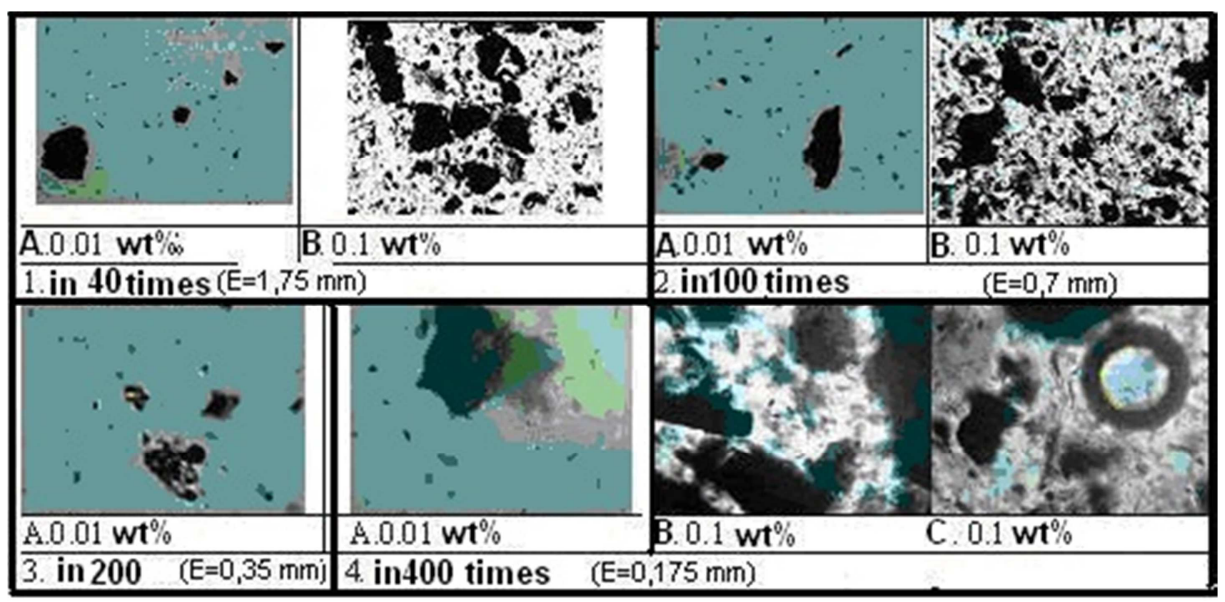

Figure 4. Micro-images of compositions before hardening (length of image E is 1)1,75;2) 0,7;3) 0,35 and 4) 0,175 mm).

According to the microscopy (Figure 4), the composition contains comparatively large aggregates of graphenes, the dimensions of which can reach $0.4 \mathrm{~mm}$ (Figure 4). In composition are stabilized rare microbubbles of air, coated with a relatively thick graphene film (up to $0.02 \mathrm{~mm}$, Figure 4C).

\subsection{Strength and Resistance Tests}

Our experiments allowed to set very considerable strengthening influence of graphene on epoxycomposite adhesion to steel surface (table 2). This influence increases with the height of grapheme concentration. At small concentrations of graphene (for example the $0,05 \mathrm{wt} \%$ ) influence on adhesion is insignificant (table 2). A microscopy shows aggregative morphology of compositions (figure 4) with the presence of graphene particles to $\mathrm{d} \approx 0,4 \mathrm{~mm}$ and including of phials of air.

Table 2. Strength of the adhesion tearing of steel cylinders $\left(S=5 \mathrm{~cm}^{2}\right)$ glued by composites with $0.01-5 \mathrm{wt} \%$ of graphene (31 and $\left.8 \mathrm{~g} / \mathrm{L}\right)$.

\begin{tabular}{|c|c|c|c|c|}
\hline Graphene, $31 \mathrm{~g} / \mathrm{L}$ in ethanol solution & Unfilled $(0 \%)$ & $0.05 \mathrm{wt} \%$ & $2 \mathrm{wt} \%$ & $5 \mathrm{wt} \%$ \\
\hline Load of tearing $\mathrm{Q}, \mathrm{kgf}$ & 70 & 65 & 190 & 240 \\
\hline$\%$ to $\mathrm{Q}$ for unfilled & $100 \%$ & $93 \%$ & $271 \%$ & $343 \%$ \\
\hline $8 \mathrm{~g} / \mathrm{L}$ in ethanol solution & Unfilled $(0 \%)$ & $1 \mathrm{wt} \%$ & $2 \mathrm{wt} \%$ & $5 \mathrm{wt} \%$ \\
\hline$\%$ to $\mathrm{Q}$ for unfilled & $100 \%$ & $112 \%$ & $175 \%$ & $130 \%$ \\
\hline
\end{tabular}

But filling with graphene do not increases any strength properties. The flexural (tensile) strength after low-filling varies little (and at $0.1 \mathrm{wt} \%$ the modulus rises), but decreases with comparatively large ones (Table 3 ). The compressive strength (Table 4) slightly increases only in the region of $0.01 \%$ by weight, in other cases it decreases.

Table 3. Flexural (tensile) strength for templates with $0,0.05-2 \mathrm{wt} \%$ of graphene.

\begin{tabular}{|c|c|c|}
\hline & Strength, $\sigma \mathrm{kgF} / \mathrm{cm}$ & Modulus, $\times 10^{3} \mathrm{kgf} / \mathrm{cm}^{2}$ \\
\hline Unfilled & 7,2 & 19 \\
\hline $0.01 \mathrm{wt} \%$ & 7,2 & 19 \\
\hline $0.05 \mathrm{wt} \%$ & 7,2 & 17 \\
\hline $0,1 \mathrm{wt} \%$ & - & 21 \\
\hline $0,5 \mathrm{wt} \%$ & - & 17 \\
\hline $1 \mathrm{wt} \%$ & - & 16 \\
\hline $2 \mathrm{wt} \%$ & 5,7 & - \\
\hline
\end{tabular}

Table 4. Strength at compression of templates with $0.01-5$ мac\% of graphene.

\begin{tabular}{llllll}
\hline Graphene, 31 g/L in ethanol solution & H (0\%) & $\mathbf{0 . 0 1} \mathbf{w t} \%$ & $\mathbf{0 . 1} \mathbf{w t} \%$ & $\mathbf{0 . 5} \mathbf{w t} \%$ & $\mathbf{1}$ wt\% \\
\hline Loading, $\mathrm{kgf}$ & 410 & 435 & 390 & 370 & 340 \\
\% to Loading for unfilled & $100 \%$ & $106 \%$ & $95 \%$ & $90 \%$ & $83 \%$ \\
8 g/L in ethanol solution & $\mathrm{H}(0 \%)$ & $1 \mathrm{wt} \%$ & $2 \mathrm{wt} \%$ & $5 \mathrm{wt} \%$ & \\
\% to Loading for unfilled & $100 \%$ & $88 \%$ & $96 \%$ & $93 \%$ & \\
\hline
\end{tabular}

Table 5. Other fixed characteristics of composites.

\begin{tabular}{lllll}
\hline & $\mathbf{H}(\mathbf{0 \%})$ & $\mathbf{0 , 0 5 w t \%}$ & $\mathbf{2 w t} \%$ & $\mathbf{5 w t} \%$ \\
\hline Time for destruction in conc. $\mathrm{HNO}_{3}$, days & 8 & 7 & 2 & 1 \\
Time for destruction in acetone: ethylacetate, days & $\geq 100$ & $\geq 100$ & $\leq 1$ & $\leq 1$ \\
Shrinkage, $\mathrm{mm}$ for $\mathrm{h}=12 \mathrm{~mm}$ & 2 & 1,5 & 0,01 & 0 \\
Abrasion, $\mathrm{mg}$ & 85 & 75 (better than $\mathrm{H})$ & $90(\approx$ to $\mathrm{H})$ & 118 (worse than $\mathrm{H})$ \\
\hline
\end{tabular}


The introduction of graphene allows shrinkage shrinkage, and at relatively high percent shrinkage disappears altogether (Table 5). Resistance to abrasion with the growth of filling is reduced (which is natural, because graphene is a soft material), although at small additives there can be interesting effects (Table 5, see for $0,05 \mathrm{wt} \%$ ) for strengthening of abrasion resistance.
In acetone, epoxy-graphenes swells speedily, and destructs in 1-2 days. It is result of corrosion-crushing (cracking, figure 5) in acetone media.

The presence of graphene in the composite does not enhance the resistance to acetone (table 6), although it may lead to less active swelling in the first hours.

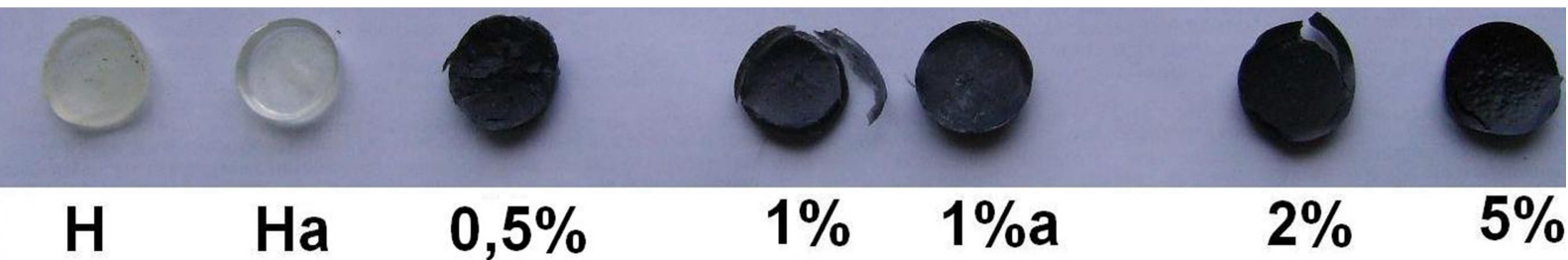

Figure 5. Visual effects of the daily effect of acetone on samples without (H, Na) and with graphene (from ethanol solution, $8 \mathrm{~g} \mid L)$.

Table 6. Swelling in a acetone: ethyl acetate (1:1) of samples with 0.01-1 $w t \%$ of graphene.

\begin{tabular}{llllll}
\hline & Unfilled & $\mathbf{0 . 0 1 w t} \%$ & $\mathbf{0 . 1 w t} \%$ & $\mathbf{0 . 5 w t} \%$ & 1wt\% \\
\hline 0 & \multicolumn{7}{l}{ Mass of simple, $\mathbf{~ m g}$} \\
0,0125 & 280 & 200 & 200 & 310 & 170 \\
0,042 & 290 & 201 & 212 & 303 & 187 \\
0,125 & 296 & 209 & 214 & 304 & 192 \\
1 & 303 & 211 & 219 & 303 & 195 \\
2 & 314 & 218 & 226 & 320 & 220 \\
8 & 319 & 223 & 225 & Destr. & Destr. \\
100 days & 339 & 233 & 234 & & \\
\hline
\end{tabular}

According classical literature (Zuev [20], on p. 71), crushing in aggressive media takes place due concentration of stresses on structure's defects. In addition to the energetic and diffusion factors, the development of cracks is determined by the relaxation processes at the boundary swollen/non-swollen polymer. The solvent causes the appearance of normal and tangential stresses in the sample. The tangential component relaxes slowly as a result of the resistance of the non-swollen nucleus at the center of the polymer, and stretch voltages appear in the swollen layer [18]. Cracking begins when the nucleus reaches the critical stress on the boundary "swollen polymer - a non-swollen core". This is aggravated by great rigidity (considerable stresses arise at small deformations) and a decrease in the diffusion rate (which contributes to the preservation of large stresses in the places of their concentration) [18].

\subsection{Heat Resistance and Fire Resistance}

The thermograms of the composites show that there is no special change in the thermal-oxidation destruction after graphene-filling as at low $(0.05 \mathrm{wt} \%)$ as relatively large (2 $\mathrm{wt} \%$, when the composition becomes high-viscosity) fillings (Figure 6). The temperature of loss of 5\% of weight after filling decreases significantly (from $270{ }^{\circ} \mathrm{C}$ for uncharged to 240 for $2 \mathrm{wt} \%$ ), and $10 \mathrm{wt} \%$ is insignificant (from almost $300^{\circ} \mathrm{C}$ to $280^{\circ} \mathrm{C}$ ).

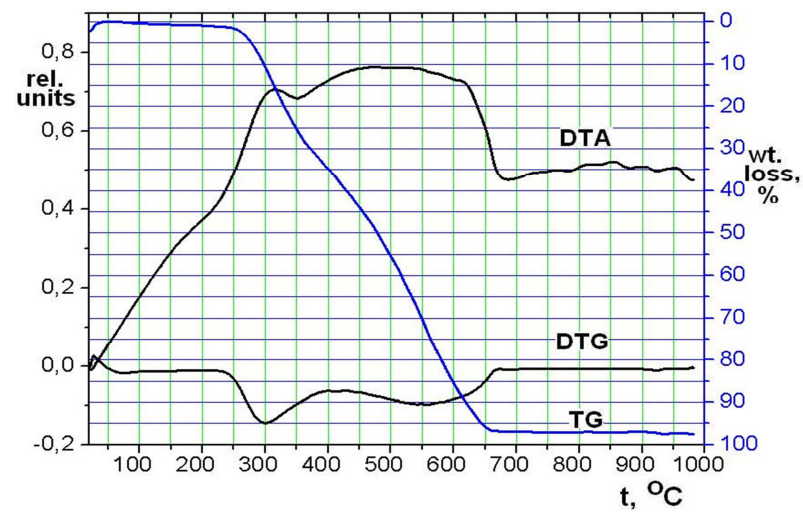

$0 \%$ of graphene (weight loss $97.4 \mathrm{wt} \%$ )

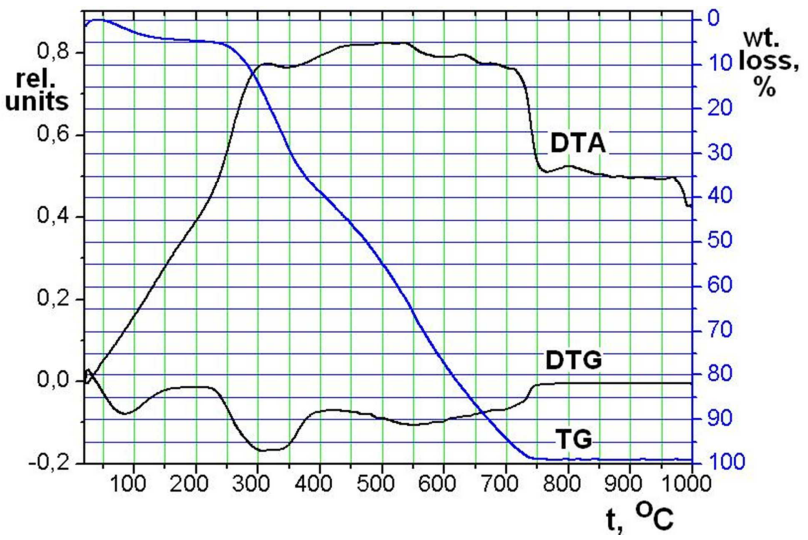

$2 \mathrm{wt} \%$ of graphene (weight loss $98.9 \mathrm{wt} \%$ )

Figure 6. Thermogrammes (TG, DTA and DTG) of composites.

\section{Conclusions}

Graphene $(0.01-5 \mathrm{wt} \%)$ is well combined with epoxy resin, giving relatively homogenous compositions with a micro-aggregate consistence of the filler.

Most of the examined strength parameters of composites after filling changed insignificantly. But substantial growth only adhesive adhesion to steel was observed - in 1.3-3.5 times (the stronger the higher the filling). At small additives 
of graphene resistance to abrasion $(0.05 \mathrm{wt} \%)$ and compressive strength $(0.01 \mathrm{wt} \%)$ can improve. Also, as the filling was growing, shrinkage decreased, disappearing to 5 $\mathrm{wt} \%$ of filling. At $0.1-5 \mathrm{wt} \%$ of filling, the compressive strength is reduced with filling, and composite becomes more sensitive to the heating as the action of a strong oxidant.

The physico-chemical resistance of composites after more than $0.1 \mathrm{wt} \%$ of graphene was sharply reduced in acidoxidizing (conc. HNO3) and aggressive organic (acetoneethyl acetate) media. The thermograms of the composites show that there is no special change in the thermal-oxidation destruction after graphene-filling as at low $(0.05 \mathrm{wt} \%)$ as relatively large ( $2 \mathrm{wt} \%)$ fillings.

\section{Acknowledgements}

The authors thank to Ph. D. Serge Shulga and Prof. Vladimir Ogenko (Institute of General and Inorganic Chemistry, NASU, Lab. of Nanotechnology, Kiev) for the supply of grapheme solutions. Strength-test equipment was provided by Head of Composite Department ISC NASU Dr. Borys Gorelov and engineer Alexander Tkachenko.

\section{References}

[1] A. K. Geim, K. S. Novoselov (2007), Nature Materials, 6, 183-187.

[2] B. M. Gorelov, A. M. Gorb, O. I. Polovina, A. B. Nadtochiy, D. L. Starokadomsky, S. V. Shulga, and V. M. Ogenko (2016) Impact of Few-Layered Graphene Plates on Structure and Properties of an Epoxy Resin. Nanotechn., Nanomat., Nanotechnology 14(4), 527-537.

[3] K. Chang, M. Hsu, H. Lu, M. Lai, P. Liu, C. Hsu, W. Ji, T. Chuang, Y. Wei, J. Yeh, W. (2014) Liu Room-temperature cured hydrophobic epoxy/graphene composites as corrosion inhibitor for cold-rolled steel. CARBON 66, 144-153.

[4] D. Starokadomsky, S. Shulga, A. Svatogor, A. Obrazkov, A. Tкасhenko (2015). Effect of Graphene $1-5 \mathrm{wt} \%$ on Epoxycomposite characteristics. INTERN. MEETING «CLUSTERS AND NANOSTRUCTURED MATERIALS》 (CNM-4), Uzhhorod, 10.2015 - P. 131.

[5] L.-Ch. Tang (2013). The effect of graphene dispersion on the mechanical properties of graphene/epoxy composites. CARBON 60 (8), 16-27

http://www.sciencedirect.com/science/article/pii/S0008622313 002698.

[6] Manjunatha G., R. George, I. Hiremath (2016). Functionalized Graphene for Epoxy Composites with Improved Mechanical Properties. American Journal of Materials Science, 6 (4A), 41-46.

[7] Y. Ni, L. Chen, K. Teng, J. Shi, X. Qian, Z. Xu, X. Tian, C. $\mathrm{Hu}$, and M. Ma (2015). Superior Mechanical Properties of Epoxy Composites Reinforced by 3D Interconnected Graphene Skeleton. ACS Appl. Mater. Interfaces, 7 (21), 11583-11591.
[8] X. Liu, X. Sun, Z. Wang, X. Shen, Y. Wu, J. Kim (2015). Planar Porous Graphene Woven Fabric/Epoxy Composites with Exceptional Electrical, Mechanical Properties, and Fracture Toughness. ACS Appl. Mater. Interfaces, 7 (38), pp 21455-21464.

[9] A. Yu, P. Ramesh, M. E. Itkis, E. Bekyarova, R. Haddon (2007). Graphite Nanoplatelet-Epoxy Composite Thermal Interface Materials. J. Phys. Chem. C, 111 (21), pp 75657569 .

[10] Starokadomsky D., Tkachenko A., Shulga S. Filling with the Graphene Nanoplates as Effective Method of Considerable Adhesion Increase to Steel of Epoxy-Composite Tapes (2017). Materials of XVI International Conference PHYSICS AND TECHNOLOGY OF THIN FILMS AND NANOSYSTEMS (ICPTTFN-XVI). - Uzhgorod, 5.2017. - P. 253.

[11] Danielle R. Klimek-McDonald, "MECHANICAL PROPERTIES OF GRAPHENE NANOPLATELET/EPOXY COMPOSITES", Ph. D. Dissertation, Michigan Technological University, 2015. - $240 \mathrm{p}$. http://digitalcommons.mtu.edu/etds/1014.

[12] Q. Li, Y. Guo, W. Li, S. Qiu, C. Zhu, X. Wei, M. Chen, C. Liu, S. Liao, Y. Gong, A. Mishra, L. Liu (2014). Ultrahigh Thermal Conductivity of Assembled Aligned Multilayer Graphene/Epoxy Composite. Chem. Mater. 26 (15), pp 44594465 .

[13] Vertically Aligned and Interconnected Graphene Networks for High Thermal Conductivity of Epoxy Composites with Ultralow Loading (2016). G. Lian, C. Tuan, L. Li, S. Jiao, Q. Wang, K. Moon, D. Cui, C. Wong. Chem. Mater., 28 (17), 6096-6104.

[14] Ultralow Electrical Percolation in Graphene Aerogel/Epoxy Composites Zhenyu Wang, Xi Shen, Ne Myo Han, Xu Liu, Ying Wu, Wenjing Ye, and Jang-Kyo Kim// Chem. Mater., 2016, 28 (18), pp 6731-6741.

[15] Graphene Aerogel/Epoxy Composites with Exceptional Anisotropic Structure and Properties. Z. Wang, X. Shen, M. Garakani, X. Lin, Y. Wu, X. Liu, X. Sun, J. Kim (2015). ACS Appl. Mater. Interfaces, 7 (9), 5538-5549.

[16] J. King, D. Klimek, I. Miskioglu (2015). Mechanical properties of graphene nanoplatelet/epoxy composites. Journal of Composite Materials 49 (6).

[17] Thermally Annealed Anisotropic Graphene Aerogels and Their Electrically Conductive Epoxy Composites with Excellent Electromagnetic Interference Shielding Efficiencies. X. Li, X. Li, K. Liao, P. Min, T. Liu, A. Dasari, Z. Yu (2016). ACS Appl. Mater. Interfaces, 8 (48), 33230-33239.

[18] I. Dobrotvor, K. Moroz, A. Buketov, P. Stuhlyak (2009). Epoxycomposites for coatings: IR-spectral and optical analysis of structure., gel-fraction in composites. Westi of Ternopol (Puluj) State Technical University, 1 33-45 (in Russian).

[19] Starokadomsky D. (2017) Epoxy Composites with 10 and 50 wt \% Micronanoiron: Strength, Microstructure, and Chemical and Thermal Resistance. Russian Journal of Applied Chemistry 90 (8), 1304-1312 ISSN 1070-4272.

[20] Zuev U. Destruction of polymers in aggressive media (in Russian). Moscow (USSR), Chimia, 1972. - 200 p. 